\title{
Mucoid conversion of Pseudomonas aeruginosa by hydrogen peroxide: a mechanism for virulence activation in the cystic fibrosis lung
}

\author{
Kalai Mathee, ${ }^{1}$ Oana Ciofu, ${ }^{2}$ Claus Sternberg, ${ }^{3}$ Peter W. Lindum, ${ }^{3}$ \\ Joan I. A. Campbell, ${ }^{2}$ Per Jensen, ${ }^{4}$ Anders H. Johnsen, ${ }^{5}$ Michael Givskov, ${ }^{3}$ \\ Dennis E. Ohman, ${ }^{1}$ Søren Molin, ${ }^{3}$ Niels Høiby ${ }^{2,4}$ and Arsalan Kharazmi ${ }^{2,4}$
}

Author for correspondence: Arsalan Kharazmi. Tel: +45354577 34. Fax: +4535456831. e-mail: kharazmi $(a)$ inet.uni2.dk

Department of Microbiology and Immunology, University of Tennessee and Veterans Affairs Medical Center, Memphis, Tennessee 38163, USA

2 Department of Bacteriology, Institute for Medical Microbiology and Immunology, University of Copenhagen, DK-2100, Denmark

3 Department of Microbiology, Technical University of Denmark, Lyngby, DK-2800, Denmark

4.5 Department of Clinical Microbiology 4 and Department of Clinical Biochemistry5, University Hospital (Rigshospitalet), Copenhagen N, DK-2200, Denmark
The leading cause of mortality in patients with cystic fibrosis (CF) is respiratory failure due in large part to chronic lung infection with Pseudomonas aeruginosa strains that undergo mucoid conversion, display a biofilm mode of growth in vivo and resist the infiltration of polymorphonuclear leukocytes (PMNs), which release free oxygen radicals such as $\mathrm{H}_{2} \mathrm{O}_{2}$. The mucoid phenotype among the strains infecting CF patients indicates overproduction of a linear polysaccharide called alginate. To mimic the inflammatory environment of the CF lung, $P$. aeruginosa PAO1, a typical non-mucoid strain, was grown in a biofilm. This was treated with low levels of $\mathrm{H}_{2} \mathrm{O}_{2}$, as if released by the PMNs, and the formation of mucoid variants was observed. These mucoid variants had mutations in mucA, which encodes an anti- $\sigma$ factor; this leads to the deregulation of an alternative $\sigma$ factor $\left(\sigma^{22}\right.$, AlgT or AlgU) required for expression of the alginate biosynthetic operon. All of the mucoid variants tested showed the same mutation, the mucA22 allele, a common allele seen in CF isolates. The mucoid mucA22 variants, when compared to the smooth parent strain PA01, (i) produced 2-6-fold higher levels of alginate, (ii) exhibited no detectable differences in growth rate, (iii) showed an unaltered LPS profile, (iv) were $\sim 72 \%$ reduced in the amount of inducible- $\beta$-lactamase and $(v)$ secreted little or no LasA protease and only showed $44 \%$ elastase activity. A characteristic $\sim 54 \mathrm{kDa}$ protein associated with alginate overproducing strains was identified as AlgE (Alg76) by $\mathrm{N}$-terminal sequence analysis. Thus, the common phenotype of the mucoid variants, which included a genetically engineered mucA22 mutant, suggested that the only mutation incurred as a result of $\mathrm{H}_{2} \mathrm{O}_{2}$ treatment was in mucA. When a $P$. aeruginosa biofilm was repeatedly exposed to activated PMNs in vitro, mucoid variants were also observed, mimicking in vivo observations. Thus, PMNs and their oxygen by-products may cause $P$. aeruginosa to undergo the typical adaptation to the intractable mu-coid form in the CF lung. These findings indicate that gene activation in bacteria by toxic oxygen radicals, similar to that found in plants and mammalian cells, may serve as a defence mechanism for the bacteria. This suggests that mucoid conversion is a response to oxygen radical exposure and that this response is a mechanism of defence by the bacteria. This is the first report to show that PMNs and their oxygen radicals can cause this phenotypic and genotypic change which is so typical of the intractable form of $P$. aeruginosa in the CF lung. These findings may provide a basis for the development of anti-oxidant and anti-inflammatory therapy for the early stages of infection in CF patients.

Keywords: Pseudomonas aeruginosa, alginate, biofilm, PMN, oxygen radicals, cystic fibrosis 


\section{INTRODUCTION}

Cystic fibrosis (CF) is a common autosomal recessive disease caused by mutations in the gene encoding the cystic fibrosis transmembrane conductance regulator (CFTR), a phosphorylation-regulated $\mathrm{Cl}^{-}$channel in the apical membrane of involved epithelia (Hilman, 1997; Sferra \& Collins, 1993). The disease is characterized by bacterial colonization and chronic airway infection that progressively destroys the lung and often leads to respiratory failure. The most common pathogen responsible for the morbidity and mortality seen in these patients is Pseudomonas aeruginosa (Koch \& Høiby, 1993). There is evidence that the CFTR contributes to host defence by acting as a bacterial ligand and thus the $C F$ defect may prevent normal clearance of $P$. aeruginosa from the respiratory tract (Pier et al., 1996). Bactericidal activity against $P$. aeruginosa has been shown to be reduced in the $\mathrm{CF}$ lung environment due to elevated levels of $\mathrm{NaCl}$ (Smith et al., 1996).

A feature of the complex CF respiratory environment that is not well understood is the selection pressure for mucoid conversion common to $P$. aeruginosa strains that thrive in this environment. The initial and intermittent colonization of the CF lungs by $P$. aeruginosa can be eradicated by early aggressive antibiotic therapy (Frederiksen et al., 1997). However, when the colony morphology of bacteria isolated from sputum samples is observed to convert to the mucoid form, the organisms can no longer be eliminated from the lungs, despite aggressive antibiotic therapy (Frederiksen et al., 1997). This mucoid conversion, readily observed in the colony morphology of the organisms found in sputum, is indicative of the overproduction of a capsule-like polysaccharide called alginate (Evans \& Linker, 1973). The potential roles of this exopolysaccharide in pathogenesis include a mechanism for bacterial adherence, a barrier to phagocytosis and a mechanism to neutralize oxygen radicals (for a review, see Govan \& Deretic, 1996). Alginate also affects leukocyte functions, such as the oxidative burst and interference with opsonization, and plays an immunomodulatory role via induction of proinflammatory cytokines and suppression of lymphocyte transformation (Pedersen, 1992; Pedersen et al., 1992).

The CF pulmonary tract is typically clogged with a viscid sputum containing a large number of polymorphonuclear leukocytes (PMNs) (Høiby et al., 1993) and it has been widely speculated that this environment of dehydration and high osmolarity may contribute to the emergence of mucoid Pseudomonas (Berry et al., 1989; DeVault et al., 1990). However, we have investigated the possibility that the effector in the CF lung responsible for the selection of mucoid variants may be the patient's own inflammatory response to the infection. Non-mucoid $P$. aeruginosa strains in the early stages of infection appear to do little harm to CF lungs (Pedersen, 1992; Pedersen et al., 1992), but the appearance of mucoid strains correlates with the formation of a bacterial biofilm containing microcolonies, the development of anti-P. aeruginosa antibodies, inflammation and a generally poor prognosis for the patient (Høiby et al., 1977; Lam et al., 1980; Pedersen, 1992; Pedersen et al., 1992). The inflammatory defence mechanisms in the CF lung against mucoid $P$. aeruginosa are dominated by PMNs and antibodies (Høiby et al., 1993). P. aeruginosa grown as a biofilm (like in the CF lung) has been shown to activate the oxidative burst of PMNs (Baltimore et al., 1989; Jensen et al., 1990; Kharazmi et al., 1986) and the complement system (Jensen et al., 1993). During phagocytosis of the bacteria, free oxygen radicals are produced which generate oxidative stress and lead to further inflammation (Brown et al., 1995; Hull et al., 1997).

In this study, we explored the role of activated PMNs and their release of toxic oxygen by-products in the $\mathrm{CF}$ lung environment, in the generation and/or selection of mucoid variants during the inflammatory response to $P$. aeruginosa that exhibits a biofilm mode of growth.

\section{METHODS}

Bacterial strains, plasmids and media. $P$. aeruginosa strains used in this study were the prototypic non-mucoid strain PAO1 (Holloway \& Morgan, 1986) and an alginate-producing CF isolate FRD1 (DeVries \& Ohman, 1994). Escherichia coli strain HB101 [F- $\Delta$ (gpt-proA)62 leuB6 supE44 ara-14 galK2 lacY1 $\Delta(m c r C-m r r)$ rpsL20 $\left(\mathrm{Str}^{\mathrm{R}}\right)$ xyl-5 mtl-1 recA13] (Boyer $\&$ Roullard-Dussoix, 1969) was used. E. coli HB101 harbouring pRK2013 [ColE1ori-Tra $\left.(\mathrm{RK} 2)^{+} ; \mathrm{Km}^{\mathrm{R}}\right]$ was used as a conjugative helper plasmid strain in triparental matings (Figurski \& Helinski, 1979). Both E. coli and P. aeruginosa were routinely cultured in $\mathrm{L}$ broth $\left(\mathrm{l}^{-1}: 10 \mathrm{~g}\right.$ tryptone, $5 \mathrm{~g}$ yeast extract, $5 \mathrm{~g} \mathrm{NaCl}$ ). LA/PIA, used in triparental matings, was a 1:1 mix of Pseudomonas Isolation Agar (Difco) and $\mathrm{L}$ agar. A defined AB medium $\left[15 \mathrm{mM}\left(\mathrm{NH}_{4}\right)_{2} \mathrm{SO}_{4}, 34 \mathrm{mM}\right.$ $\mathrm{Na}_{2} \mathrm{HPO}_{4} .2 \mathrm{H}_{2} \mathrm{O}, 22 \mathrm{mM} \mathrm{KH}_{2} \mathrm{PO}_{4}, 51 \mathrm{mM} \mathrm{NaCl}, 4 \mathrm{mM}$ sodium citrate, $1 \mathrm{mM} \mathrm{MgCl}_{2}, 0.1 \mathrm{mM} \mathrm{CaCl}, 0.01 \mathrm{mM}$ FeEDTA, pH 7.0] was used to grow cells in flow chambers. To provide an early indication of the mucoid phenotype of $P$. aeruginosa, blue agar plates were used (Høiby, 1975). Sucrose sensitivity was tested on $\mathrm{L}$ agar plates containing $5 \%$ sucrose. Antibiotics were used at the following concentrations unless otherwise indicated $\left(\mu \mathrm{g} \mathrm{ml}^{-1}\right)$ : ampicillin, 50; kanamycin, 30; carbenicillin, 300 .

Isolation of PMNs. PMNs were isolated from citrated human peripheral blood from normal healthy individuals by dextran sedimentation and Lymphoprep (Nyegaard) gradient centrifugation as described previously (Jensen \& Kharazmi, 1991). Erythrocytes were removed by hypotonic lysis and PMNs were resuspended in Kreb-Ringer solution $(130 \mathrm{mM} \mathrm{NaCl}$, $5 \mathrm{mM} \mathrm{KCl}, 0.9 \mathrm{mM} \mathrm{CaCl}_{2}, 1.2 \mathrm{mM} \mathrm{MgCl}_{2}, 15 \mathrm{mM} \mathrm{NaH}_{2} \mathrm{PO}_{4}$, $\mathrm{pH} 7 \cdot 2$ ) containing $1 \%$ human serum albumin at a cell concentration of $2 \times 10^{7}$ cells $\mathrm{ml}^{-1}$.

Biofilm mode of growth. Cultures of $P$. aeruginosa strain PAO1 were grown in an apparatus containing dual continuous-flow chambers with a glass surface for bacterial adherence (Fig. 1). Procedures used were as described by Wolfaardt et al. (1994). AB medium was passed through flow cells at $0 \cdot 2 \mathrm{~mm} \mathrm{~s}^{-1}$. P. aeruginosa was inoculated upstream of the growth chamber as a single $0.5 \mathrm{ml}$ pulse $\left(\sim 5 \times 10^{9}\right.$ cells in stationary phase), filling the chamber while the medium pump was off. The flow was resumed $1 \mathrm{~h}$ after inoculation. After $24 \mathrm{~h}$ incubation at $37^{\circ} \mathrm{C}$, the growth of the biofilm was 


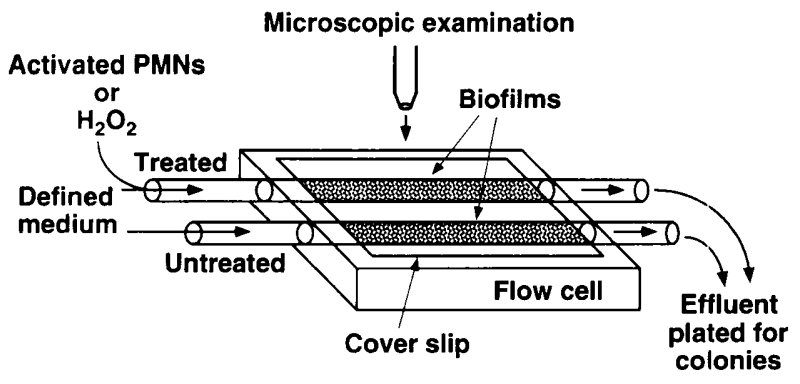

Fig. 1. Schematic representation of a flow cell used to mimic the biofilm mode of growth of $P$. aeruginosa that is typical in the CF lung. Cultures of $P$. aeruginosa PAO1 were grown in an apparatus containing dual continuous-flow chambers with a glass surface for bacterial adherence. One biofilm of $P$. aeruginosa in the apparatus was subjected either to activated human peripheral blood PMNs or to sublethal concentrations of $\mathrm{H}_{2} \mathrm{O}_{2}$ as described in Methods. The other chamber in the apparatus served as an untreated control.

monitored using a phase-contrast microscope and a singlelayer biofilm was observed. One biofilm of $P$. aeruginos $a$ in the apparatus was subjected either to human peripheral blood PMNs $\left(2 \times 10^{7}\right.$ cells $\left.\mathrm{ml}^{-1}\right)$ activated with the chemotactic peptide $\mathrm{f}$-Met-Leu-Phe $\left(10^{-5} \mathrm{M}\right)$ or to sublethal concentrations of $\left.\mathrm{H}_{2} \mathrm{O}\right)(1.0 \mathrm{mM}$ or $2.5 \mathrm{mM})$ for $60 \mathrm{~min}$, two to three times a day. The other chamber in the apparatus served as an untreated control. Bacteria from the effluent were plated each day to obtain $\sim 200$ colonies on $\mathrm{L}$ or Blue agar.

Construction of a mucA22 mutant of $\boldsymbol{P}$. aeruginosa PAO1. Plasmid pKMG180 (Fig. 2) was formed by cloning a $2.0 \mathrm{~kb}$ EcoRI-HindIII DNA fragment containing the mucA22 allele from the alginate-producing CF isolate FRD1 (DeVries \& Ohman, 1994) into the blunt-ended SmaI site of pEX100T (Schweizer \& Hoang, 1995), a mobilizable suicide plasmid containing a $s a c B$ gene that confers sucrose sensitivity in $P$. aeruginosa. This plasmid was transferred into strain PAO1 from $E$. coli and the merodiploids that formed by homologous recombination with the chromosome were selected with carbenicillin (i.e. $300 \mu \mathrm{g} \mathrm{ml} \mathrm{m}^{-1}$ resistance conferred by bla). Such strains were then grown without selection to permit a second cross-over to occur, which excised the plasmid and left the mutant allele in the chromosome. Colonies appearing on agar plates containing sucrose to select for loss of the plasmidencoded $s a c B$ were screened for the mucoid phenotype and carbenicillin sensitivity. The presence of the mucA22 mutation in one mucoid derivative (PDO300) was confirmed by DNA sequence analysis.

PCR and sequencing. AmpliTaq FS DNA polymerase was obtained from Perkin-Elmer Cetus. PCR amplification of the $m u c A$ region of the mucoid variants was carried out as described by the manufacturers, using primers KAL 25 (5'CGAATTCCATGGAAGCCTGACACAGCGGCAATGCC$\left.3^{\prime}\right)$ and KAL32 (5'-CCCAAGCTTCTCCTCAGCGGTTTTCCA(;GCTGGCTGC-3'). DNA sequencing was done using an Applied Biosystems automated DNA Sequencer (37.3A) and the Perkin-Elmer Cetus Dye Terminator Kit with primers PWL-1 (5'-CCAAGAGAGGTATCGCTATG-3'), PWL-int (5'-GGTCGGTCGCCTGGCGGTCG-3') and PWL-rev (5'CCAG(;CTGGCTGCCCGAGCG-3').
Membrane fractionation and peptide sequencing. The outermembrane fraction of $P$. aeruginosa strains was obtained by Sarkosyl treatment of sonicated extracts as described by Filip et al. (1973). A $54 \mathrm{kDa}$ protein characteristic of mucoid CF variants was blotted onto a PVDF membrane and subjected to $\mathrm{N}$-terminal sequence analysis in a Precise 494A Protein Sequencer (Perkin-Elmer Cetus) using procedures and reagents as supplied by the manufacturer.

Determination of alginate concentration. Cells were incubated at $37^{\circ} \mathrm{C}$ in $\mathrm{L}$ broth with rapid aeration for $18 \mathrm{~h}$ under standardized conditions and removed by centrifugation. The amount of alginate in the culture supernatant was precipitated using an equal volume of $2 \%(\mathrm{w} / \mathrm{v})$ cetylpyridinium chloride followed by centrifugation at 10000 r.p.m. for $10 \mathrm{~min}$ at room temperature. The alginate pellet was resuspended in $5 \mathrm{ml} 1 \mathrm{M}$ $\mathrm{NaCl}$ and reprecipitated with $5 \mathrm{ml}$ cold 2-propanol and centrifuged at 10000 r.p.m. for $10 \mathrm{~min}$. The final alginate pellet was resuspended in $500-4000 \mu \mathrm{l}$ saline depending on the quantity of alginate made. The amount of alginate was determined using a borate/carbazole method (Knutson \& Jeanes, 1968) with D-mannuronate lactone (Sigma) used to calibrate a standard curve. Briefly, a solution of purified alginate $(30 \mu \mathrm{l})$ was mixed with $1.0 \mathrm{ml}$ borate/sulfuric acid reagent $\left(10 \mathrm{mM} \mathrm{H}_{3} \mathrm{BO}_{3}\right.$ in concentrated $\left.\mathrm{H}_{2} \mathrm{SO}_{4}\right)$ and $30 \mu \mathrm{l}$ carbazole reagent $(0 \cdot 1 \%$ in ethanol) was added. The mixture was heated to $55^{\circ} \mathrm{C}$ for $30 \mathrm{~min}$ and the alginate concentration was determined spectrophotometrically at $500 \mathrm{~nm}$.

Measurement of $\boldsymbol{\beta}$-lactamase activity. Strains were grown with induction in the presence of benzylpenicillin $\left(500 \mathrm{mg} \mathrm{l}^{-1}\right.$ in $\mathrm{L}$ broth) for $2.5 \mathrm{~h}$, lysed by sonication and assayed for $\beta$ lactamase activity using a spectrophotometric assay as previously described by Campbell et al. (1997) and Giwercman et al. (1991).

Protease activity. Strains were incubated at $37{ }^{\circ} \mathrm{C}$ in $\mathrm{L}$ broth with rapid aeration for $18 \mathrm{~h}$ under standardized conditions and cells were removed by centrifugation. LasA protease (staphylolytic) activity was determined in a spectrophotometric assay, essentially as described by Kessler et al. (1993) by measuring the rate of lysis of a suspension of Staphylococcus aureus cells. LasB protease (elastase) activity was determined in a spectrophotometric assay using elastin-Congo red (Sigma) as a substrate as described by Ohman et al. (1980).

\section{RESULTS}

\section{Isolation of $\mathrm{Alg}^{+}$variant after repeated exposure of $P$. aeruginosa PAO1 biofilm to sublethal concentrations of $\mathrm{H}_{2} \mathrm{O}_{2}$}

We hypothesized that activated PMNs and their release of toxic oxygen by-products in the CF lung environment could play a role in the generation and/or selection of mucoid variants during the inflammatory response to $P$. aeruginosa. The biofilm mode of growth by $P$. aeruginosa in the CF lung may play an important role in enhancing this response to reactive oxygen intermediates released by activated PMNs. To mimic the biofilm mode of growth seen in vivo, P. aeruginosa PAO1 (a commonly used wild-type strain) was grown in continuous-flow culture chambers (i.e., flow-cells; Fig. 1) as described by Wolfaardt et al. (1994). Responses to oxidative stress, leading to the expression of specific genes, is known to occur by a variety of mechanisms in prokaryotic and 
Table 1. Phenotypic comparison of $P$. aeruginosa wild-type $P A O 1$ and its mucA22 variants obtained by gene replacement (PDO300) or $\mathrm{H}_{2} \mathrm{O}_{2}$ treatment of a biofilm

\begin{tabular}{|c|c|c|c|c|c|}
\hline Strain* & Genotype & $\begin{array}{c}\text { Alginate } \\
{\left[\mu g\left(m l^{\text {culture }}\right.\right.} \\
\left.\text { supernatant })^{-1}\right]\end{array}$ & $\begin{array}{c}\text { Induced } \\
\beta \text {-lactamase } \\
\text { levels }(\mathrm{mU}) \dagger\end{array}$ & $\begin{array}{c}\text { LasA protease } \\
{\left[\Delta A_{595} \min ^{-1}\right.} \\
\left.(\text { mg protein })^{-1}\right]\end{array}$ & $\begin{array}{c}\text { LasB protease } \\
{\left[\Delta A_{495} \min ^{-1}\right.} \\
\left.(\mathrm{mg} \text { protein })^{-1}\right]\end{array}$ \\
\hline PAO1 & Wild-type & ND & $234 \cdot 5 \pm 40 \cdot 3$ & $128 \cdot 1 \pm 7 \cdot 4$ & $15 \cdot 7 \pm 7 \cdot 3$ \\
\hline PDO300 & $m u c A 22$ & $170 \cdot 5 \pm 9 \cdot 4$ & $66 \cdot 0 \pm 20 \cdot 2$ & $16 \cdot 0 \pm 1 \cdot 6$ & $5 \cdot 7 \pm 2 \cdot 4$ \\
\hline $\mathrm{H}_{2} \mathrm{O}_{2}$-induced & $m u c A 22$ & $229 \cdot 1 \pm 59 \cdot 5$ & $63 \cdot 2 \pm 12 \cdot 8$ & $11 \cdot 9 \pm 4 \cdot 7$ & $5 \cdot 1 \pm 1 \cdot 7$ \\
\hline
\end{tabular}

ND, Not detected.

* $P$. aeruginosa PAO1 is a non-mucoid wild-type strain. PDO300 is a mucA22 derivative of PAO1 constructed by gene replacement (see Fig. 2). ' $\mathrm{H}_{2} \mathrm{O}_{2}$-induced' represents the eight mucA22 derivatives obtained by treatment of PAO1 in a biofilm (see Fig. 1), which all produced approximately the same results in these tests.

tOne milliunit of $\beta$-lactamase activity is defined as the amount of enzyme required to hydrolyse $1 \mathrm{nmol}$ nitrocefin $\min ^{-1}(\mathrm{mg} \text { protein })^{-1}$. All strains showed basal uninduced $\beta$-lactamase levels of $12-16.5 \mathrm{mU}$.

eukaryotic species (Scandalios, 1997; Shirasu et al., 1996; Sundaresan et al., 1995). To simulate exposure to reactive oxygen species, as would occur from activated PMNs in the lungs, biofilms of $P$. aeruginosa were subjected to sublethal concentrations of $\mathrm{H}_{2} \mathrm{O}_{2}$. It has been established that the cells in the effluent from a biofilm provide a fair representation of the cells in a biofilm (Christensen et al., 1998). Thus, samples from the effluent of a flow cell were periodically plated on $\mathrm{L}$ agar and screened for the formation of mucoid colonies. Bacteria from the effluents of the flow cell were plated on agar and screened for the formation of mucoid colonies. In three independent experiments, after 3-8 d treatment, mucoid colonies were often observed $(\sim 0.1 \%)$ in the culture treated with $\mathrm{H}_{2} \mathrm{O}_{2}$. Control chambers, where biofilms were not challenged, showed no mucoid colonies. Alginate was overproduced by all the mucoid variants of PAO1 and the amounts of alginate were approximately the same $\left(229 \mu \mathrm{g}\right.$ alginate $\left.\mathrm{ml}^{-1}\right)$ for all but the parental PAO1 which made virtually none (Table 1).

\section{Mucoid conversion is due to a mutation in mucA encoding an anti- $\sigma$ factor}

When $P$. aeruginosa strains infecting CF patients convert to the mucoid phenotype in vivo, they frequently display a mutation in the gene encoding MucA (Martin et al., 1993). MucA is an anti- $\sigma$ factor that controls the activity of $\sigma^{22}$, a $22 \mathrm{kDa}$ alternative $\sigma$ factor encoded by algT (also known as algU) (DeVries \& Ohman, 1994; Hershberger et al., 1995; Martin et al., 1994). To examine whether the mucoid variants of $P$. aeruginosa obtained by $\mathrm{H}_{2} \mathrm{O}_{2}$ treatment also had mucA defects, the chromosomal DNA from this region of these strains was amplified by PCR and subjected to sequence analysis. The results showed that in eight mucoid variants examined (obtained in two independent experiments), all had the same mutation; this was a deletion of a $G$ residue in a string of five $G$ residues located at $426-430 \mathrm{bp}$ in the mucA ORF (Fig. 2). This gives rise to

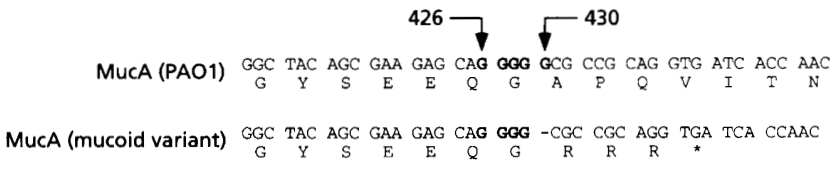

Fig. 2. Sequence analysis of $\mathrm{Alg}^{+}$variants. The entire mucA region was PCR-amplified using primers KAL25 and KAL32 (see Methods) and sequenced. The sequence presented is the only region where the $\mathrm{Alg}^{+}$variants differed from the $\mathrm{Alg}^{-}$parent, PAO1. All the mucoid variants had the same mutationdeletion of a $G$ residue in a string of five $G$ residues located at $426-430 \mathrm{bp}$ in the mucA ORF, resulting in premature termination of translation as indicated by the asterisk.

premature termination of translation, resulting in the production of a truncated MucA protein.

\section{Construction of a PAO1 derivative with a mucA22 allele}

To provide an isogenic control strain for comparison between PAO1 and the mucoid variants isolated in the biofilm experiment, a gene replacement technique was used to generate a mucA22 derivative of PAO1 called PDO300 (Fig. 3). This was accomplished by cloning a fragment containing the mucA22 allele from the alginate-producing CF isolate FRD1 (DeVries \& Ohman, 1994) into pEX100T (Schweizer \& Hoang, 1995), a mobilizable suicide plasmid containing $s a c B$ that confers sucrose sensitivity in $P$. aeruginosa. This plasmid was transferred into strain PAO1 from E. coli and the merodiploids that formed by homologous recombination with the chromosome were selected with carbenicillin. A second cross-over occurred when these strains were grown without selection, which excised the plasmid and left the mutant allele in the chromosome. Colonies exhibiting a mucoid phenotype, sucrose resistance and carbenicillin sensitivity were isolated. DNA sequence analysis of one mucoid derivative, PDO300, confirmed the presence of the mucA22 mutation. 


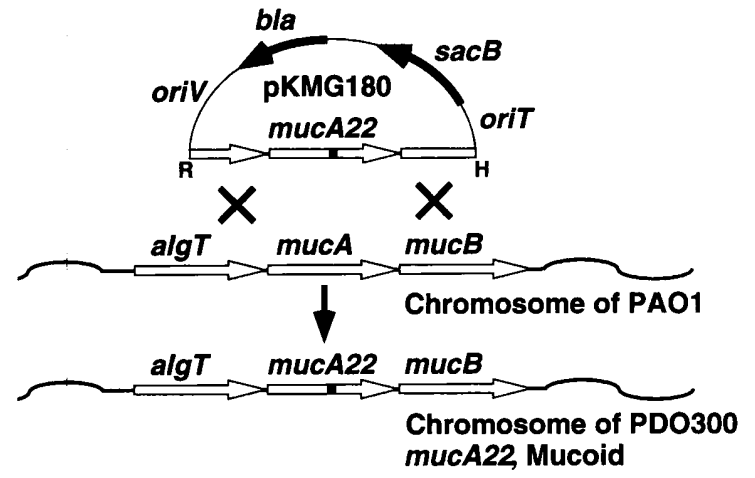

Fig. 3. Construction of a muCA22 mutant of $P$. aeruginosa PAO1. An isogenic mucA22 mucoid variant of wild-type strain PAO1 was cohstructed for comparison with the mucA22 variants obtained during $\mathrm{H}_{2} \mathrm{O}_{2}$ treatment. The diagram shows the method used to obtain a strain altered by a specific single base pair deletion in mucA in the chromosome as described in Methods.

Alginate was overproduced by PDO300 (170 $\mu$ g alginate $\mathrm{ml}^{-1}$ ) whereas the parental PAO1 made virtually none (Table 1).

\section{Phenotypic characteristics of the alginate-producing variants}

Compared to $P$. aeruginosa strains from environmental and non-CF clinical sources, the strains responsible for chronic pulmonary disease in CF patients often display a number of interesting phenotypic abnormalities [e.g. alginate overproduction, altered LPS, new outer-membrane proteins (OMPs), altered antibiotic sensitivities, etc.]. We examined whether the mucA22 mucoid variants derived from exposure to $\mathrm{H}_{2} \mathrm{O}_{2}$ might show similar phenotypic changes. The rates of growth in $\mathrm{L}$ broth of all the mucA22 mucoid strains were virtually identical and a PFGE analysis of chromosomal DNA revealed no obvious genetic rearrangement (data not shown). The LPS ladders observed after SDS-PAGE were unchanged in the mucA22 variants of both $\mathrm{H}_{2} \mathrm{O}_{2}$ treatment and genetic manipulation when compared to the smooth strain, PAO1 (data not shown). The antibiotic resistance profile of mucA22 variants was identical to that observed with PAO1 (antibiotics tested: piperacillin, aztreonam, ceftazidime, imipenem, meropenem, colistin, ciprofloxacin, ofloxacin, tobramycin and netilmycin; data not shown).

\section{The amount of inducible- $\beta$-lactamase is reduced in the alginate-producing variants}

$P$. aeruginosa isolates from CF patients typically produce high levels of chromosomal $\beta$-lactamase, a group 1 cephalosporinase encoded by ampC (Campbell et al., 1997; Giwercman et al., 1991). Since most of the mucoid $\mathrm{CF}$ isolates also harbour a mutation in $m u c A$, we

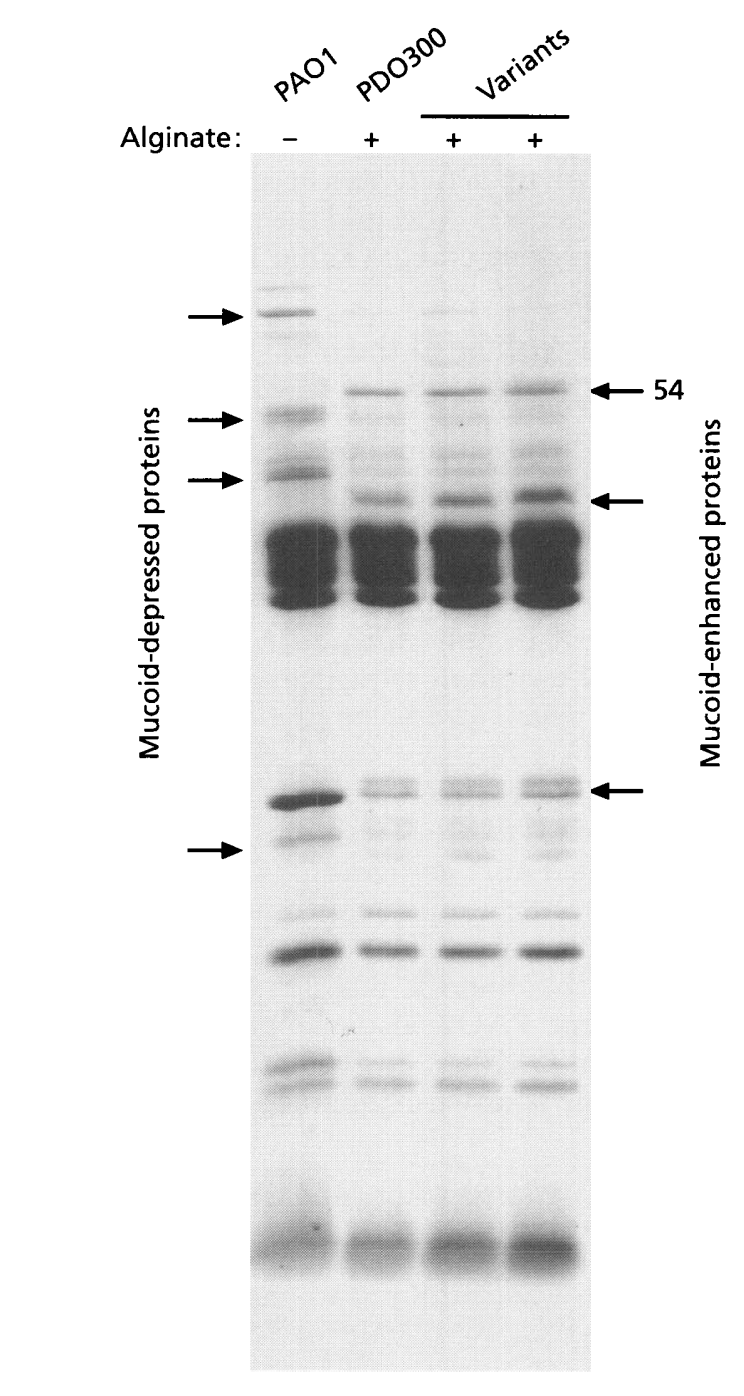

Fig. 4. Silver-stained SDS-polyacrylamide gel showing the OMP profiles of $P$. aeruginosa wild-type $\mathrm{PAO} 1$ and its mucA22 variants obtained by gene replacement (PDO300) or $\mathrm{H}_{2} \mathrm{O}_{2}$ treatment of a biofilm. The arrows indicate the migration of differentially expressed proteins. A $54 \mathrm{kDa}$ protein characteristic of mucoid CF variants is indicated.

wanted to determine if high-level $\beta$-lactamase expression is associated with this particular mutation. However, all of the mucA22 variants produced a low basal level of $\beta$ lactamase that was inducible. In addition, the induced level of $\beta$-lactamase (following treatment with $500 \mu \mathrm{g}$ benzylpenicillin $\mathrm{ml}^{-1}$ ) was reduced to $\sim 72 \%$ in all the alginate-producing variants (Table 1 ).

\section{Protease production is reduced in the alginate- producing variants}

$P$. aeruginosa secretes a number of proteases, including elastase, LasA (staphylolytic) protease and alkaline protease (Kharazmi, 1989; Morihara \& Homma, 1985). The mucA22 variants were characterized for elastolytic and LasA protease activities relative to the wild-type 
PAO1. Optimal culture conditions for protease production and measurement were used to evaluate extracellular levels of elastolytic and LasA protease activities. Analysis of the mucoid mucA22 variants of PAO1 showed that elastolytic activity was reduced by $\sim 66 \%$ as compared to parental PAO1 and the presence of LasA protease was barely detectable (Table 1 ).

\section{Outer-membrane profiles of the alginate-producing variants showed the presence of a $\sim 54 \mathrm{kDa}$ protein}

Alginate-overproducing strains have been shown to have OMP profiles with a prominent $\sim 54 \mathrm{kDa}$ protein which is not observed in non-mucoid strains (Goldberg \& Ohman, 1987; Grabert et al., 1990). This characteristic protein was also observed in all of the mucA22 mucoid variants and absent in non-mucoid PAO1 (Fig. 4). We performed an $\mathrm{N}$-terminal sequence analysis on the purified protein which produced the sequence: XaaAsn-Ser-Gly-Glu-Ala-Pro-Lys-Xaa-Phe-Gly-Leu-AspVal-Lys-Ile-Thr. Apart from Asn at position 2, this sequence corresponds to the $\mathrm{N}$ terminus of $\mathrm{Alg} \mathrm{E}$ (Alg76) previously identified in $P$. aeruginosa (Chu et al., 1991). The discrepancy in the amino acid composition may be due to strain differences. The comparison of OMP profiles between the mucA22 mucoid variants and the non-mucoid parent PAO1 also showed that the expression of several OMPs is up-regulated, although the expression of some is down-regulated.

\section{Isolation of $\mathrm{Alg}^{+}$variants after repeated exposure of a $P$. aeruginosa PAO1 biofilm to activated PMNs}

A direct approach was employed to test our hypothesis that activated PMNs, by release of toxic oxygen byproducts, are responsible in the CF lung environment for the generation and/or selection of mucoid variants during the inflammatory response to $P$. aeruginosa. A PAO1 biofilm was then repeatedly exposed to activated human peripheral blood PMNs. Bacteria from the flow cell effluent were plated onto agar, incubated and screened for mucoid colony formation. Several mucoid variants were isolated in two independent experiments in the culture treated with PMNs. No mucoid colonies appeared from control chambers where biofilms were not challenged. These PMN-derived mucoid variants exhibited the same phenotype as the mucA22 mucoid variants derived from exposure to $\mathrm{H}_{2} \mathrm{O}_{2}$ (data not shown). This further supports the hypothesis that mucoid conversion of $P$. aeruginosa in the CF lung may result from interaction with PMNs.

\section{DISCUSSION}

In this study, we provide evidence that activated PMNs and their release of toxic oxygen by-products in the CF lung environment may play a role in the generation and/or selection of mucoid variants during the inflammatory response to $P$. aeruginosa which is typically present in a biofilm. We were able to mimic the biofilm mode of growth seen in vivo by growing $P$. aeruginosa
PAO1 in continuous-flow culture chambers (Fig. 1). Mucoid variants of PAO1 were isolated from a biofilm that was repeatedly exposed to activated human peripheral blood PMNs and sublethal concentrations of $\mathrm{H}_{2} \mathrm{O}_{2}$.

P. aeruginosa strains infecting CF patients often convert to the mucoid phenotype in vivo and these strains frequently have mutations in the gene encoding MucA (Martin et al., 1993). MucA is an anti- $\sigma$ factor, located in the inner membrane, which is part of a protein complex that controls the activity of $\sigma^{22}$, a $22 \mathrm{kDa}$ alternative $\sigma$ factor encoded by algT (algU) (Mathee et al., 1997). $\sigma^{22}$ is a member of the extracytoplasmic function subfamily of eubacterial RNA polymerase $\sigma$ factors involved in the regulation of extracytoplasmic functions (DeVries \& Ohman, 1994; Hershberger et al., 1995; Lonetto et al., 1994; Martin et al., 1994). The loss of MucA protein results in the deregulation of $\sigma^{22}$ and leads to the activation of $\sigma^{22}$-dependent promoters, including those for the alginate biosynthetic genes (Mathee et al., 1997; Schurr et al., 1996; Xie et al., 1996). The mucoid variants of $P$. aeruginosa obtained by $\mathrm{H}_{2} \mathrm{O}_{2}$ treatment also had a $m u c A$ defect - deletion of a $G$ residue in a string of five $G$ residues located at $426-430 \mathrm{bp}$ in the $m u c A$ ORF. Even though other mutations in mucA could theoretically produce the same effect, this particular region seems to be a hot-spot for mutations, probably due to slip-strand mispairing in this string of $G$ residues during DNA replication. A premature termination codon in $m u c A$ was thus formed as a result of the deletion, leading to the formation of a MucA protein truncated in the C-terminal domain. This results in the loss of the periplasmic domain of this transmembrane protein, and thus the anti- $\sigma$ factor activity of MucA on $\sigma^{22}$ is lost (Mathee et al., 1997; Schurr et al., 1996; Xie et al., 1996). Interestingly, $25 \%$ of mucoid clinical isolates from $C F$ patients also show this same $G$ residue deletion, which is known as the mucA22 allele (Boucher et al., 1997).

To compare the phenotypic differences of the isolated mucoid variants with a PAO1 derivative that only differed in the mucA allele, an isogenic strain was constructed by homologous recombination between a DNA fragment containing the mucA22 allele from alginate-producing CF isolate FRD1 and PAO1 (DeVries \& Ohman, 1994). The presence of the mucA22 mutation in the $\mathrm{Alg}^{+}$strain (PDO300) was confirmed by DNA sequencing. Inactivation of $m u c A$ in non-mucoid $P$. aeruginosa PAO1 was sufficient to cause constitutive alginate production; this result and data from others (Martin et al., 1993), confirm that MucA functions as a negative regulator of alginate production.

All investigations of the isolated $\mathrm{Alg}^{+}$variants isolated in the flow-cell experiments were run in parallel with analysis of the genetically engineered mutant strain, PDO300. The $\mathrm{Alg}^{+}$variants made 2-6-fold higher levels of alginate than the parent strain (Table 1). Alginate production has been associated with altered rates of 
growth and altered LPS. The $\mathrm{Alg}^{+}$variants exhibited no detectable differences in growth rate. Most mucoid strains of CF origin are rough or semi-rough due to an altered LPS with shortened O side-chains (Høiby et al., 1993). However, the LPS profile was unchanged in the mucA22 variants when compared to the smooth parent strain, PAO1. Thus neither a mutation in mucA nor alginate production were sufficient to promote the altered LPS profile observed in many mucoid CF isolates.

Alginate production has also been implicated in the development of increased resistance to antibiotics in $\mathrm{CF}$ isolates. $P$. aeruginosa isolates from CF patients typically produce high levels of chromosomal $\beta$-lactamase (group 1 cephalosporinase, encoded by $a m p C$ ) which has been attributed to the major resistance mechanism seen in chronic infections (Campbell et al., 1997; Giwercman et al., 1991). The amount of inducible- $\beta$-lactamase was reduced to $\sim 72 \%$ in all the alginate-producing variants (Table 1), so the resistance phenotype typical of CF strains is apparently not associated with the mucA22 allele. The inability to attain full inducibility in the mucoid variants may be due to the presence of capsularlike polysaccharide that prevents benzylpenicillin from entering the cells.

$P$. aeruginosa secretes a number of proteases which are believed to play a major role in the pathogenesis of this organism, especially during acute infections (Kharazmi, 1989; Morihara \& Homma, 1985). These proteases, elastase, LasA (staphylolytic) protease and alkaline protease, have been inversely correlated with alginate production (Ohman \& Chakrabarty, 1982). The mucoid $m u c A 22$ variants of $\mathrm{PAO} 1$ showed little or no secretion of LasA protease and only $44 \%$ elastase activity compared to parent strain PAO1 (Table 1). However, it is not clear if this phenotype is associated directly with the mutation in $m u c A$ or indirectly through another gene activated by $\sigma^{22}$, the alternative $\sigma$ factor.

The OMP profiles of alginate-overproducing strains show the presence of a prominent $\sim 54 \mathrm{kDa}$ protein which is absent in non-mucoid strains (Goldberg \& Ohman, 1987; Grabert et al., 1990). There is some evidence that the $54 \mathrm{kDa}$ protein could be the product of algE (Rehm et al., 1994). algE is transcribed as part of an $18 \mathrm{~kb}$ operon of biosynthetic genes and its product may be involved in polymer export to the bacterial surface (Chu et al., 1991; Rehm et al., 1994). The $\sim 54 \mathrm{kDa}$ protein was observed in all $\mathrm{Alg}^{+}$variants of PAO1 (Fig. 4) and we showed directly that this protein is the algE gene product. The OMP profile analysis also showed that the mucA22 defect (which deregulates $\sigma^{22}$ activity) led to changes in the expression of several OMPs, some of which were up-regulated and others were downregulated. Experiments are under way to discern the nature of these proteins.

The results described above showed that activated PMNs, or $\mathrm{H}_{2} \mathrm{O}_{2}$ released by these cells, can cause mucoid conversion of $P$. aeruginosa when growing in the biofilm mode as it does in the CF lung. Mucoid conversion following $\mathrm{H}_{2} \mathrm{O}_{2}$ treatment was associated with the generation of the mucA22 allele, a common mutation that occurs when $P$. aeruginosa undergoes mucoid conversion in the CF lung. Mutations in mucA, which encodes an anti- $\sigma$ factor, lead to the deregulation of an alternative $\sigma$ factor $\left(\sigma^{22}, \mathrm{Alg} \mathrm{T}\right.$ or $\left.\mathrm{AlgU}\right)$ required for expression of the alginate biosynthetic operon. Phenotypic characterization of the mucoid variants, which included a genetically engineered mucA22 mutant, showed that all had similar characteristics and suggested that the only mutation incurred as a result of $\mathrm{H}_{2} \mathrm{O}_{2}$ treatment was in mucA.

We propose that mucoid conversion is a response to exposure to toxic oxygen by-products and that this response is probably a mechanism of defence by the bacteria. It has been shown previously that $\mathrm{H}_{2} \mathrm{O}_{2}$ can induce gene activation in plants and mammalian cells. The activated genes have been proposed to protect the cells against the toxicity of reactive oxygen species (Scandalios, 1997; Shirasu et al., 1996; Sundaresan et al., 1995). Our findings demonstrate a similar phenomenon in bacteria. Furthermore, these findings provide evidence for the first time suggesting that $\mathrm{H}_{2} \mathrm{O}_{2}$ released by PMNs, the predominant cells of inflammation, is an important factor in the conversion of $P$. aeruginosa to the intractable mucoid form in the CF lung. Additional studies would be warranted to elucidate the definitive role of PMNs in the mucoid conversion. Our findings reveal new possibilities in the design of preventive and therapeutic measures using antioxidants and anti-inflammatory agents in $\mathrm{CF}$ patients with $P$. aeruginosa infections.

\section{ACKNOWLEDGEMENTS}

We thank A. Asnovski, M. Ainouz and T. Wassermann for technical assistance. We also acknowledge the helpful suggestions provided by Jean Gustin, Joanne Johnston, Søren Møller and David Ambruster. This work was supported in part by Public Health Service grant AI-19146 from the National Institute of Allergy and Infectious Diseases (D.O.), by Veterans Administration Medical Research Funds (D.O.) and by a grant from the Danish Biotechnology Program (A.K., M.G. and S.M.).

\section{REFERENCES}

Baltimore, R. S., Christie, C. D. \& Smith, G. J. (1989). Immunohistopathologic localization of Pseudomonas aeruginosa in lungs from patients with cystic fibrosis. Implications for the pathogenesis of progressive lung deterioration. Am Rev Respir Dis 140, 1650-1661.

Berry, A., DeVault, J. D. \& Chakrabarty, A. M. (1989). High osmolarity is a signal for enhanced algD transcription in mucoid and nonmucoid Pseudomonas aeruginosa strains. J Bacteriol 171, 2312-2317.

Boucher, J. C., Yu, H., Mudd, M. H. \& Deretic, V. (1997). Mucoid Pseudomonas aeruginosa in cystic fibrosis: characterization of $m u c$ mutations in clinical isolates and analysis of clearance in a mouse model of respiratory infection. Infect Immun 65, $3838-3846$. 
Boyer, H. W. \& Roullard-Dussoix, D. (1969). A complementation analysis of the restriction and modification of DNA in Escherichia coli. J Mol Biol 41, 459-472.

Brown, R. K., McBurney, A., Lunec, J. \& Kelly, F. J. (1995). Oxidative damage to DNA in patients with cystic fibrosis. Free Radic Biol Med 18, 801-806.

Campbell, J., Ciofu, O. \& Høiby, N. (1997). Pseudomonas aeruginosa isolates from patients with cystic fibrosis have different $\beta$-lactamase expression phenotypes but are homogeneous in the $a m p C-a m p R$ genetic region. Antimicrob Agents Chemother 41, 1380-1384.

Christensen, B. B., Sternberg, C., Andersen, J. B., Eberl, L., Moller, S., Givskov, M. \& Molin, S. (1998). Establishment of new genetic traits in a microbial biofilm community. Appl Environ Microbiol 64, 2247-2255.

Chu, L., May, T. B., Chakrabarty, A. M. \& Misra, T. K. (1991). Nucleotide sequence and expression of the algE gene involved in alginate biosynthesis by Pseudomonas aeruginosa. Gene 107, $1-10$

DeVault, J. D., Kimbara, K. \& Chakrabarty, A. M. (1990). Pulmonary dehydration and infection in cystic fibrosis: evidence that ethanol activates gene expression and induction of mucoidy in Pseudomonas aeruginosa. Mol Microbiol 4, 737-745.

DeVries, C. A. \& Ohman, D. E. (1994). Mucoid-to-nonmucoid conversion in alginate-producing Pseudomonas aeruginosa often results from spontaneous mutations in $\operatorname{alg} T$, encoding a putative alternative sigma factor, and shows evidence for autoregulation. $J$ Bacteriol 176, 6677-6687.

Evans, L. R. \& Linker, A. (1973). Production and characterization of the slime polysaccharide of Pseudomonas aeruginosa. J Bacteriol 116, 915-924.

Figurski, D. \& Helinski, D. R. (1979). Replication of an origincontaining derivative of plasmid RK2 dependent on a plasmid function provided in trans. Proc Natl Acad Sci USA 76, 1648-1652.

Filip, C., Fletcher, G., Wulff, J. L. \& Earhart, C. F. (1973). Solubilization of the cytoplasmic membrane of Escherichia coli by the ionic detergent sodium-lauryl sarcosinate. J Bacteriol 115, $717-722$

Frederiksen, B., Koch, C. \& Høiby, N. (1997). Antibiotic treatment of initial colonization with Pseudomonas aeruginosa postpones chronic infection and prevents deterioration of pulmonary function in cystic fibrosis. Pediatr Pulmonol 23, 330-335.

Giwercman, B., Jensen, E. T., Høiby, N., Kharazmi, A. \& Costerton, J. W. (1991). Induction of beta-lactamase production in Pseudomonas aeruginosa biofilm. Antimicrob Agents Chemother 35, 1008-1010.

Goldberg, J. B. \& Ohman, D. E. (1987). Construction and characterization of Pseudomonas aeruginosa algB mutants: role of algB in high-level production of alginate. J Bacteriol 169, 1593-1602.

Govan, J. R. \& Deretic, V. (1996). Microbial pathogenesis in cystic fibrosis: mucoid Pseudomonas aeruginosa and Burkholderia cepacia. Microbiol Rev 60, 539-574.

Grabert, E., Wingender, J. \& Winkler, U. K. (1990). An outer membrane protein characteristic of mucoid strains of Pseudomonas aeruginosa. FEMS Microbiol Lett 56, 83-87.

Hershberger, C. D., Ye, R. W., Parsek, M. R., Xie, Z. \& Chakrabarty, A. M. (1995). The algT (algU) gene of Pseudomonas aeruginosa, a key regulator involved in alginate biosynthesis, encodes an alternative $\sigma$ factor $\left(\sigma^{\mathrm{E}}\right)$. Proc Natl Acad Sci USA 92, 7941-7945.
Hilman, B. C. (1997). Genetic and immunologic aspects of cystic fibrosis. Ann Allergy Asthma Immunol 79, 379-390.

Høiby, N. (1975). Prevalence of mucoid strains of Pseudomonas aeruginosa in bacteriological specimens from patients with cystic fibrosis and patients with other diseases. Acta Pathol Microbiol Scand Suppl 83, 549-552.

Høiby, N., Flensborg, E. W., Beck, B., Friis, B., Jacobsen, L. \& Jacobsen, S. V. (1977). Pseudomonas aeruginosa infection in cystic fibrosis. Diagnostic and prognostic significance of Pseudomonas aeruginosa precipitins determined by means of crossed immunoelectrophoresis. A survey. Scand J Resp Dis 58, 65-79.

Høiby, N., Giwercman, B., Jensen, T., Johansen, H. K., Kronborg, G., Pressler, T. \& Kharazmi, A. (1993). Immune response in cystic fibrosis-helpful or harmful? In Clinical Ecology of Cystic Fibrosis, pp. 133-141. Edited by H. Scobar \& others. Amsterdam: Excerpta Medica.

Holloway, B. W. \& Morgan, A. F. (1986). Genome organization in Pseudomonas. Annu Rev Microbiol 40, 79-105.

Hull, J., Vervaart, P., Grimwood, K. \& Phelan, P. (1997). Pulmonary oxidative stress response in young children with cystic fibrosis. Thorax 52, 557-560.

Jensen, E. T., Kharazmi, A., Lam, K., Costerton, J. W. \& Høiby, N. (1990). Human polymorphonuclear leukocyte response to Pseudomonas aeruginosa grown in biofilms. Infect Immun 58, 2383-2385.

Jensen, E. T., Kharazmi, A., Garred, P., Kronborg, G., Fomsgaard, A., Mollnes, T. E. \& Høiby, N. (1993). Complement activation by Pseudomonas aeruginosa biofilms. Microb Pathog 15, 377-388.

Jensen, P. \& Kharazmi, A. (1991). Computer-assisted image analysis assay of human neutrophil chemotaxis in vitro. J Immunol Methods 144, 43-48.

Kessler, E., Safrin, M., Olson, J. C. \& Ohman, D. E. (1993). Secreted LasA of Pseudomonas aeruginosa is a staphylolytic protease. $J$ Biol Chem 268, 7503-7508.

Kharazmi, A. (1989). Interactions of Pseudomonas aeruginosa proteases with the cells of the immune system. In Basic and Clinical Aspects of Pseudomonas aeruginosa: Antibiotics and Chemotherapy, pp. 42-49. Edited by N. Høiby, S. S. Pedersen, G. H. Shand, G. Döring \& I. A. Holder. Basel: Karger.

Kharazmi, A., Schiøtz, P. O., Høiby, N., Baek, L. \& Döring, G. (1986). Demonstration of neutrophil chemotactic activity in the sputum of cystic fibrosis patients with Pseudomonas aeruginosa infection. Eur J Clin Invest 16, 143-148.

Knutson, C. A. \& Jeanes, A. (1968). A new modification of the carbazole analysis: application to heteropolysaccharides. Anal Biochem 24, 470-481.

Koch, C. \& Høiby, N. (1993). Pathogenesis of cystic fibrosis. Lancet 341, 1065-1069.

Lam, J., Chan, R., Lam, K. \& Costerton, J. W. (1980). Production of mucoid microcolonies by Pseudomonas aeruginosa within infected lungs in cystic fibrosis. Infect Immun 28, 546-556.

Lonetto, M. A., Brown, K. L., Rudd, K. E. \& Buttner, M. J. (1994). Analysis of the Streptomyces coelicolor sigE gene reveals the existence of a subfamily of eubacterial RNA polymerase $\sigma$ factors involved in the regulation of extracytoplasmic functions. Proc Natl Acad Sci USA 91, 7573-7577.

Martin, D. W., Schurr, M. J., Mudd, M. H., Govan, J. R., Holloway, B. W. \& Deretic, V. (1993). Mechanism of conversion to mucoidy in Pseudomonas aeruginosa infecting cystic fibrosis patients. Proc Natl Acad Sci USA 90, 8377-8381. 
Martin, D. W., Schurr, M. J., Yu, H. \& Deretic, V. (1994). Analysis of promoters controlled by the putative sigma factor AlgU regulating conversion to mucoidy in Pseudomonas aeruginosa: relationship to $\sigma^{\mathrm{E}}$ and stress response. J Bacteriol 176, 6688-6696.

Mathee, K., McPherson, C. J. \& Ohman, D. E. (1997). Posttranslational control of the $\operatorname{alg} T(\operatorname{alg} U)$-encoded $\sigma^{22}$ for expression of the alginate regulon in Pseudomonas aeruginosa and localization of its antagonist proteins MucA and $\mathrm{MucB}(\mathrm{AlgN}) . J$ Bacteriol 179, 3711-3720.

Morihara, K. \& Homma, J. Y. (1985). Pseudomonas proteases. In Bacterial Enzymes and Virulence, pp. 41-79. Edited by I. A. Holder. Boca Raton, FL: CRC Press.

Ohman, D. E. \& Chakrabarty, A. M. (1982). Utilization of human respiratory secretions by mucoid Pseudomonas aeruginosa of cystic fibrosis origin. Infect Immun 37, 662-669.

Ohman, D. E., Cryz, S. J. \& Iglewski, B. H. (1980). Isolation and characterization of a Pseudomonas aeruginosa PAO mutant that produces altered elastase. $J$ Bacteriol 142, 836-842.

Pedersen, S. S. (1992). Lung infection with alginate-producing, mucoid Pseudomonas aeruginosa in cystic fibrosis. Acta Pathol Microbiol Immunol Scand Suppl 28, 1-79.

Pedersen, S. S., Moller, H., Espersen, F., Sorensen, C. H., Jensen, T. \& Høiby, N. (1992). Mucosal immunity to Pseudomonas aeruginosa alginate in cystic fibrosis. Acta Pathol Microbiol Immunol Scand 100, 326-334.

Pier, G. B., Grout, M., Zaidi, T. S., Olsen, J. C., Johnson, L. G., Yankaskas, J. R. \& Goldberg, J. B. (1996). Role of mutant CFTR in hypersusceptibility of cystic fibrosis patients to lung infections. Science 271, 64-67.

Rehm, B. H., Boheim, G., Tommassen, J. \& Winkler, U. K. (1994). Overexpression of algE in Escherichia coli: subcellular localization, purification, and ion channel properties. J Bacteriol 176, 5639-5647.
Scandalios, J. G. (editor) (1997). Oxidative Stress and the Molecular Biology of Antioxidant Defenses. Cold Spring Harbor, NY: Cold Spring Harbor Laboratory.

Schurr, M. J., Yu, H., Martinez-Salazar, J. M., Boucher, J. C. \& Deretic, V. (1996). Control of AlgU, a member of the $\sigma^{\mathbf{E}}$-like family of stress sigma factors, by the negative regulators MucA and MucB and Pseudomonas aeruginosa conversion to mucoidy in cystic fibrosis. J Bacteriol 178, 4997-5004.

Schweizer, H. P. \& Hoang, T. T. (1995). An improved system for gene replacement and $x y l E$ fusion analysis in Pseudomonas aeruginosa. Gene 158, 15-22.

Sferra, T. J. \& Collins, F. S. (1993). The molecular biology of cystic fibrosis. Annu Rev Med 44, 133-144.

Shirasu, K., Dixon, R. A. \& Lamb, C. (1996). Signal transduction in plant immunity. Curr Opin Immunol 8, 3-7.

Smith, J. J., Travis, S. M., Greenberg, E. P. \& Welsh, M. J. (1996). Cystic fibrosis airway epithelia fail to kill bacteria because of abnormal airway surface fluid. Cell 85, 229-236.

Sundaresan, M., Yu, Z. X., Ferrans, V. J.; Irani, K. \& Finkel, T. (1995). Requirement for generation of $\mathrm{H}_{2} \mathrm{O}_{2}$ for platelet-derived growth factor signal transduction. Science 270, 296-299.

Wolfaardt, G. M., Lawrence, J. R., Robarts, R. D., Caldwell, S. J. \& Caldwell, D. E. (1994). Multicellular organization in a degradative biofilm community. Appl Environ Microbiol 60, 434-446.

Xie, Z. D., Hershberger, C. D., Shankar, S., Ye, R.W. \& Chakrabarty, A. M. (1996). Sigma factor-anti-sigma factor interaction in alginate synthesis: inhibition of AlgT by MucA. $J$ Bacteriol 178, 4990-4996.

Received 7 December 1998; revised 22 February 1999; accepted 11 March 1999. 